\title{
A descentralização das competências ambientais e a fiscalização do desmatamento na Amazônia
}

\author{
Jair Schmitt \\ Universidade de Brasília / Centro de Desenvolvimento Sustentável, \\ Programa de Pós-Graduação em Desenvolvimento Sustentável \\ Brasília / DF - Brasil
}

Fernando Paiva Scardua

Universidade de Brasilia / Faculdade UnB Gama

Brasilia / DF - Brasil

\begin{abstract}
O objetivo do artigo é discutir a descentralização das competências ambientais e suas implicações para a fiscalização ambiental, especialmente para coibir o desmatamento ilegal na Amazônia. O procedimento metodológico adotado baseou-se na pesquisa bibliográfica, complementada com a análise de dados das taxas anuais de desmatamento. Conclui-se que a competência prevalente de fiscalizar $85,6 \%$ do desmatamento que ocorre na Amazônia é dos estados. Contudo, quem mais realiza a fiscalização de forma supletiva é o órgão ambiental federal, o que pode comprometer sua capacidade instalada para atender às suas demais demandas. Portanto, é necessário investir na estruturação dos órgãos ambientais estaduais para atuarem na fiscalização efetiva do desmatamento.
\end{abstract}

Palavras-chave: descentralização ambiental; fiscalização ambiental; desmatamento na Amazônia; federalismo; proteção ambiental.

La descentralización de los poderes ambientales y la fiscalización de la deforestación en la Amazonia

El objetivo de este artículo es discutir la descentralización de poderes en el medio ambiente y sus implicaciones para la fiscalización contra la deforestación ilegal en la Amazonía. El procedimiento metodológico adoptado se basa en la búsqueda bibliográfica sobre el tema, complementado con análisis de datos de las tasas anuales de deforestación. Se concluye que el poder dominante de la inspección de $85,6 \%$ de la deforestación que ocurre en la Amazonía es de los estados. Sin embargo, quien más realiza la inspección de forma complementaria es la agencia federal ambiental, que puede comprometer su

DOI: http://dx.doi.org/10.1590/0034-7612131456

Artigo recebido em 2 mar. 2014 e aceito em 24 mar. 2015. 
capacidad para cumplir con sus otras demandas. Por lo tanto, es necesario invertir en la estructuración de las agencias ambientales estatales para trabajar en el control efectivo de la deforestación.

Palabras clave: descentralización ambiental; fiscalización ambiental; deforestación en la Amazonia; federalismo; protección del medio ambiente.

The environmental decentralization and the enforcement of Amazon deforestation

The objective of this paper is to discuss the environmental decentralization and its implications for environmental enforcement, especially against illegal deforestation in the Amazon. The methodological procedure adopted was based on the literature search, supplemented by data analysis of annual deforestation rates. It is concluded that $85,6 \%$ of the deforestation occurring in the Amazon is the competence of inspection is the states. However, who else performs the inspection of supplementary form is the federal environmental agency, which may compromise their capacity to meet their other demands. Therefore, it is necessary to invest in the structuring of state environmental agencies to work in the effective control of deforestation.

Keywords: environmental decentralization; environmental enforcement; Amazon deforestation; federalism; environmental protection.

\section{Introdução}

O modelo federativo de Estado adotado pelo Brasil tem como uma das suas premissas a descentralização de competências entre os entes federativos (estados, Distrito Federal e municípios). A descentralização das competências ambientais começou a ocorrer a partir da Constituição Federal (CF) de 1988 (Brasil, 2010) de forma pontual e sem uniformidade, exigindo assim um ato normativo mais objetivo e definitivo.

A necessidade de dar maior segurança jurídica à sociedade, somada à busca de maior celeridade na análise de impactos ambientais de atividades e empreendimentos e à emissão das respectivas licenças, fez com que fosse regulamentado o art. 23 da CF (Brasil, 2010) para disciplinar o assunto. Ocorre que isso também teve um rebatimento na atuação do Estado sobre as atividades e condutas lesivas ao meio ambiente, o que motivou a questionar: quais as implicações da descentralização ambiental para a fiscalização do desmatamento ilegal na Amazônia?

Essa indagação é sustentada pelo fato de que o desmatamento na Amazônia é um assunto que causa grande preocupação na agenda ambiental brasileira e internacional. Nos últimos cinco anos houve um grande avanço com a redução anual das taxas de desmatamento e acredita-se que em boa medida isso é fruto das ações de fiscalização ambiental promovidas, principalmente, pelo órgão ambiental federal. Porém, diante da nova ordem jurídica que repassa a responsabilidade de fiscalizar aos demais entes federativos, especialmente aos estados e Distrito Federal, paira a dúvida sobre que implicações poderá haver na aplicação do instrumento punitivo para conter o desmatamento. 
Portanto, o objetivo deste artigo é discutir a descentralização ambiental promovida pela regulamentação do art. 23 da CF e suas implicações para a fiscalização ambiental no combate ao desmatamento ilegal na Amazônia.

O texto está organizado em três partes principais. A primeira parte trata da descentralização das competências ambientais, promovidas pela nova Lei Complementar no 140 (LC 140) (Brasil, 2011). A segunda parte aborda aspectos gerais sobre o desmatamento na Amazônia e seus fatores de motivação. Na terceira parte são abordados os fundamentos da fiscalização ambiental, a lógica de coerção administrativa que o Estado aplica para promover a proteção dos recursos naturais e a atuação federal para fiscalizar o desmatamento na Amazônia.

\section{Procedimentos metodológicos}

Este trabalho caracteriza-se como uma discussão teórica, delineada predominantemente a partir da pesquisa bibliográfica envolvendo o tema abordado. A pesquisa bibliográfica foi programada procurando descrever e analisar as variáveis afetas aos seguintes aspectos: descentralização ambiental, desmatamento na Amazônia, fiscalização ambiental.

Entre as principais fontes bibliográficas pesquisadas, destacam-se aquelas de cunho normativo (leis e decretos) publicadas no Diário Oficial da União (DOU), que permitiram entender o ordenamento ambiental e o papel de fiscalização da administração pública nas diversas esferas. Também foram utilizados artigos científicos pesquisados junto ao portal de periódicos da Coordenação de Aperfeiçoamento de Pessoal de Nível Superior (Capes) (Capes, 2012) publicados nos últimos 10 anos, cujos termos de busca estão relacionados ao tema da pesquisa. E, ainda, foram analisados documentos técnicos do Ministério do Meio Ambiente (MMA) e dados dos sistemas informatizados do Instituto Brasileiro do Meio Ambiente e dos Recursos Naturais Renováveis (Ibama), que propiciaram melhor entendimento do contexto e interpretação das informações.

Também foi empregada a técnica de observação participante (Mann, 1975), que proporcionou aos pesquisadores participarem de atividades na administração pública federal que envolviam o tema abordado. No caso, eles participaram de reuniões e de todas as etapas do processo de fiscalização ambiental, o que possibilitou conhecer com mais riqueza o seu modus operandi, de tal sorte que contribuiu para melhor entender a execução da descentralização da política ambiental.

Complementarmente, foram realizados cruzamentos e análises entre os dados espaciais do desmatamento na Amazônia gerados pelo Monitoramento da Floresta Amazônica Brasileira por Satélite (Prodes) (Inpe, 2014), os dados de domínio fundiário sistematizados pelo Serviço Florestal Brasileiro (SBF), visando identificar as competências para a autorização de desmatamento e de exploração florestal. Esses dados contribuíram para robustecer o discurso e alguns achados da pesquisa bibliográfica.

Cabe salientar que, muito embora o tema descentralização apresente uma rica produção científica, poucas publicações existem sobre fiscalização ambiental, especialmente 
quando se trata do Brasil e do recorte Amazônia. Assim, o conhecimento decorrente da experiência laboral dos pesquisadores que trabalham a mais de 10 anos com fiscalização e gestão ambiental no serviço público contribuiu para a análise, descrição dos achados e interpretação.

\section{A descentralização das competências em meio ambiente}

A descentralização é um processo pelo qual são transferidas responsabilidades de algumas funções do governo central para os governos locais. Ela é considerada um dos aspectos mais importantes a ser debatido no modelo de Estado ou na reforma desse Estado, sob a égide da bandeira da democracia. O consenso tem conduzido o entendimento de que a descentralização é uma grande solução para superar vários problemas de gestão do Estado e do sistema político. O contexto da história mais recente do Brasil também induz a essa perspectiva, tendo em vista os anos de governo ditatorial e o estabelecimento de um Estado nacionalista.

Com a redemocratização no país na década de 1980, a nova CF foi forjada à luz dos ideais democráticos e em contraposição ao regime militar anteriormente vigente (Arretche, 1996). O modelo de república federativa estabelecido soma-se aos outros 27 países federativos, que totalizam cerca de $40 \%$ da população mundial (Andersen, 2009). Com a promulgação da nova Carta Mãe foram previstas diversas competências entre os entes federados, caracterizando assim a descentralização de poderes.

Embora seja evidente que a descentralização é um relevante fator para a democracia, há algumas polêmicas em torno dela que, segundo Arretche (1996), podem ser tratadas como mitos. Como nenhum sistema é perfeito, deve-se encontrar um equilíbro para se obter uma boa governança (Andersson e Ostrom, 2008). Em síntese, há vantagens e desvantagens na descentralização (Baker, 2005; Epstein, 1997; Johnson, 2001; Gibson e Lehoucq, 2003; Libecap, 1989; Meinzen-Dick, 2007; Platteau, 2004; Platteau e Gaspart, 2003; Shivakumar, 2005), tais como as relatadas a seguir.

Quanto às vantagens da descentralização: o conhecimento local possibilita saber como gerir melhor os recursos naturais; sistemas paralelos de elaboração de regras, interpretação e aplicação reduzem a probabilidade de falhas em uma grande região; pode haver maior capilaridade do governo local. E, em relação às desvantagens da descentralização: a auto-organização local é muito dispendiosa; há conflitos entre os usuários locais de recursos naturais; muitos usuários locais não investem tempo e energia na regulamentação do uso dos recursos naturais; também há altos custos políticos; há medo de ter seus esforços derrubados por autoridades superiores; ocorrência de tiranias locais (captura do poder por elites dominantes); risco de haver estagnação na gestão dos recursos.

O debate sobre descentralização e centralização da política ambiental brasileira é fruto de intenso processo de desenvolvimento da sociedade brasileira, vindo espelhar sua maturidade no teor da CF (Brasil, 2010) que, se por um lado é avançada sob o aspecto am- 
biental, por outro enfrenta grandes desafios para sua implementação (Scardua e Bursztyn, 2003). Apenas os países que tiveram suas Constituições elaboradas a partir da década de 1970 é que retrataram a importância ambiental em seus textos, como é o caso de Chile, Panamá, Grécia, Portugal, China, Polônia, Argélia, Peru, Argentina, Espanha, entre outros (Milaré, 2009).

A institucionalização da gestão ambiental no Brasil iniciou nos anos 1970 (Hochstetler, e Keck, 2007) e nos anos 1980 foram impulsionadas a criação de órgãos estaduais de meio ambiente e a formulação das políticas ambientais. No entanto, quase todos os estados da região amazônica só formularam seu marco regulatório e institucional de meio ambiente nos anos 1990. Até então, esse aparato legal enfrentava problemas de ordem política, econômica, financeira e de recursos humanos, relegando a questão ambiental ao segundo plano nas agendas governamentais (Bursztyn, Assunção e Bursztyn, 2004).

A Carga Magna de 1988 criou um modelo único de federalismo, composto por três níveis, ao reconhecer a União, os estados e Distrito Federal e os municípios como entes, e que passa a ser uma tendência mundial ao afirmar as autonomias locais (Milaré, 2009). O texto constitucional definiu diversas competências entre esses entes federados, o que foi convencionado a chamar de federalismo cooperativo, caracterizando assim a descentralização ou repartição de poderes. Essas competências foram desmembradas em competências comuns e competências concorrentes. $\mathrm{O}$ art. 23 dispõe sobre as competências comuns ou competências administrativas entre a União, os estados e Distrito Federal e os municípios, ou seja, trata-se da execução de tarefas relacionadas ao meio ambiente. Nas competências comuns está prevista a proteção do meio ambiente, com destaque para flora e fauna, o controle da poluição e a proteção às paisagens naturais e aos sítios arqueológicos.

Por sua vez, a competência concorrente ou competência legislativa, prevista no art. 24, trata da elaboração de leis e atos normativos. As matérias que os entes federativos podem legislar concorrentemente relacionadas ao meio ambiente são sobre direito urbanístico, florestas, caça, pesca, fauna, conservação da natureza, defesa do solo e dos recursos naturais, proteção ao meio ambiente, controle da poluição e proteção ao patrimônio histórico, cultural, artístico, turístico, paisagístico e responsabilidade por danos ambientais. Cabe lembrar que, na competência concorrente, a União estabelece normas gerais de interesse nacional e os entes federados poderão estabelecer normas suplementares sobre assuntos de interesse regional (estados e Distrito Federal) ou local (municípios), sem contrariar ou contrapor a norma geral (Milaré, 2009).

Em relação às competências comuns, está previsto que leis complementares fixariam normas para a cooperação entre a União e os estados, o Distrito Federal e os municípios, tendo em vista o equilíbrio do desenvolvimento e do bem-estar em âmbito nacional. Foi o que ensejou a LC 140 (Brasil, 2011), abordada mais adiante. No entanto, algumas das competências comuns relacionadas ao meio ambiente já foram operacionalizadas em outros atos normativos, carecendo agora de aperfeiçoamento e ajustes para obtenção de melhores resultados. Entre os temas que de alguma forma já foram descentralizados, podemos citar a gestão 
florestal que trata da concessão florestal pelos diversos entes federados. A legislação sobre o assunto permite que os estados autorizem a exploração de florestas e formações sucessoras, tanto de domínio público como de domínio privado (Brasil, 2006, 2011, 2012).

Acolhida na CF (Brasil, 2010), a Lei da Política Nacional de Meio Ambiente (Brasil, 1981), que entrou em vigor em 1981, representou uma iniciativa de vanguarda na época como aparato legal, embora a motivação real da sua criação estivesse mais voltada a atender condicionantes para o Brasil obter financiamentos internacionais do que apenas preocupada com o meio ambiente. Uma de suas características era a tendência de descentralização das ações de gestão ambiental na esfera federal devido à complexa tarefa de o poder público tratar essa temática. Mas, na prática, não foi bem isso o que aconteceu, pois, com a criação do Ibama em 1989, essa perspectiva foi freada. Até então, as ações de gestão ambiental eram muito tímidas e fragmentadas, distribuídas entre os quatro órgãos que originaram esse órgão federal de meio ambiente.

O Ibama, criado antes mesmo do Ministério do Meio Ambiente, passou a ser a referência como órgão ambiental nacional, detendo grandes poderes. Porém, com o passar dos anos, os desafios que surgiram eram superiores à sua capacidade de resposta, muitas vezes porque esses desafios tinham peculiaridades locais e, dessa forma, poderiam ser mais bem tratados pelos órgãos estaduais ou municipais de meio ambiente.

Visando desafogar o trabalho da União e dos órgãos estaduais de meio ambiente, e no intuito de dar continuidade à descentralização ambiental, o Poder Executivo encaminhou um projeto de lei à Câmara dos Deputados em 2007, vindo a somar-se aos demais sobre o mesmo assunto que se encontravam naquela casa. Depois de alguns anos em trâmites e sem causar grandes alardes no debate legislativo, foi sancionada a LC 140 (Brasil, 2011), que fixa normas, nos termos dos incisos III, VI e VII do caput e parágrafo único do art. 23 da CF (Brasil, 2010). Esta legislação define a cooperação entre a União, os estados, o Distrito Federal e os municípios, nas ações administrativas decorrentes do exercício da competência comum relativas à proteção das paisagens naturais notáveis, à proteção do meio ambiente, ao combate à poluição em qualquer de suas formas e à preservação das florestas, da fauna e da flora, além de alterar a Política Nacional de Meio Ambiente.

No contexto da época, a relevância da descentralização ambiental pode ser atribuída a uma das medidas do Programa de Aceleração do Crescimento (PAC), que se trata de um conjunto de políticas econômicas planejadas cujo objetivo era o crescimento econômico do país. O PAC foi composto inicialmente por cinco blocos de medidas, a saber: medidas de infraestrutura, incluindo a infraestrutura social, como habitação, saneamento e transporte em massa (principal bloco); medidas para estimular crédito e financiamento; desoneração tributária; medidas fiscais de longo prazo; e melhoria do marco regulatório na área ambiental. Essa última medida traduz-se principalmente em descentralizar as competências em meio ambiente, disciplinando parte do art. 23 da CF (Brasil, 2010).

À luz da LC 140 (Brasil, 2011), excetuando-se algumas competências privativas da União, a competência pela lavratura dos autos de infração ambiental e para instaurar os 
processos administrativos para a apuração das infrações à legislação ambiental, é o órgão que detém a competência do licenciamento ou autorização do empreendimento ou atividade objeto da infração (Brasil, 2011). Ou seja, vincula-se a aplicação das sanções administrativas ao órgão ambiental do ente federativo que tiver a competência para realizar o licenciamento ambiental ou autorizar o uso de recursos naturais (órgão concedente). Essa tendência de vinculação também já era defendida na doutrina do direito ambiental visto que quem deve resolver os problemas é quem está perto deles (Machado, 2002). Como exemplo, já havia a previsão legal de que quem fiscaliza ambientalmente postos revendedores, postos de abastecimento, instalações de sistemas retalhistas e postos flutuantes de combustíveis é quem o licenciou (Conama, 2000). Segundo Teixeira e Santana (1995), para atingir a descentralização, um dos aspectos essenciais é descentralizar também as estruturas fiscalizadoras para que "as atividades de fiscalização e controle permeiem organicamente a rede administrativa, tornando a função fiscalizadora mais próxima da fonte de execução da atividade correspondente e, portanto, da população".

Contudo, há uma ressalva no art. 17 da LC 140 que não impede o exercício pelos entes federativos da atribuição comum de fiscalização de empreendimentos e atividades efetiva ou potencialmente poluidores ou utilizadores de recursos naturais (Brasil, 2011). Porém, nesse caso prevalece o auto de infração ambiental lavrado por órgão que detenha a atribuição de licenciamento ou autorização. Em suma, qualquer órgão ambiental poderá realizar a fiscalização ambiental em um empreendimento ou atividade que cause ou possa causar poluição, ou que utilize ou que possa utilizar recursos naturais. No entanto, caso mais de um órgão lavre um auto de infração, vai prevalecer o auto daquele órgão que tiver a competência para licenciar ou autorizar o empreendimento ou atividade. Além disso, quando houver iminência ou ocorrência de degradação da qualidade ambiental, o ente federativo que tiver conhecimento do fato deverá determinar medidas para evitá-la, fazer cessá-la ou mitigá-la, comunicando imediatamente ao órgão competente para as providências cabíveis (Brasil, 2011).

Portanto, a prevalência do poder de punir a violação das regras ambientais é vinculada à competência do ente federativo que licencia ou autoriza, no caso de mais de um órgão realizar a autuação, sem restringir o poder coercitivo de todos os órgãos ambientais.

\section{0 desmatamento na Amazônia}

Uma das grandes preocupações que domina a agenda ambiental brasileira e internacional diz respeito ao desmatamento ilegal na Amazônia. Durante muitos anos as taxas eram elevadíssimas, contudo, nos últimos cinco anos obteve-se um alento com redução sucessiva dessas taxas (gráfico 1), embora não seja motivo de grandes comemorações em face dos milhares de quilômetros quadrados de floresta que são sucumbidos anualmente. 
Gráfico 1

Evolução das taxas de desmatamento na Amazônia

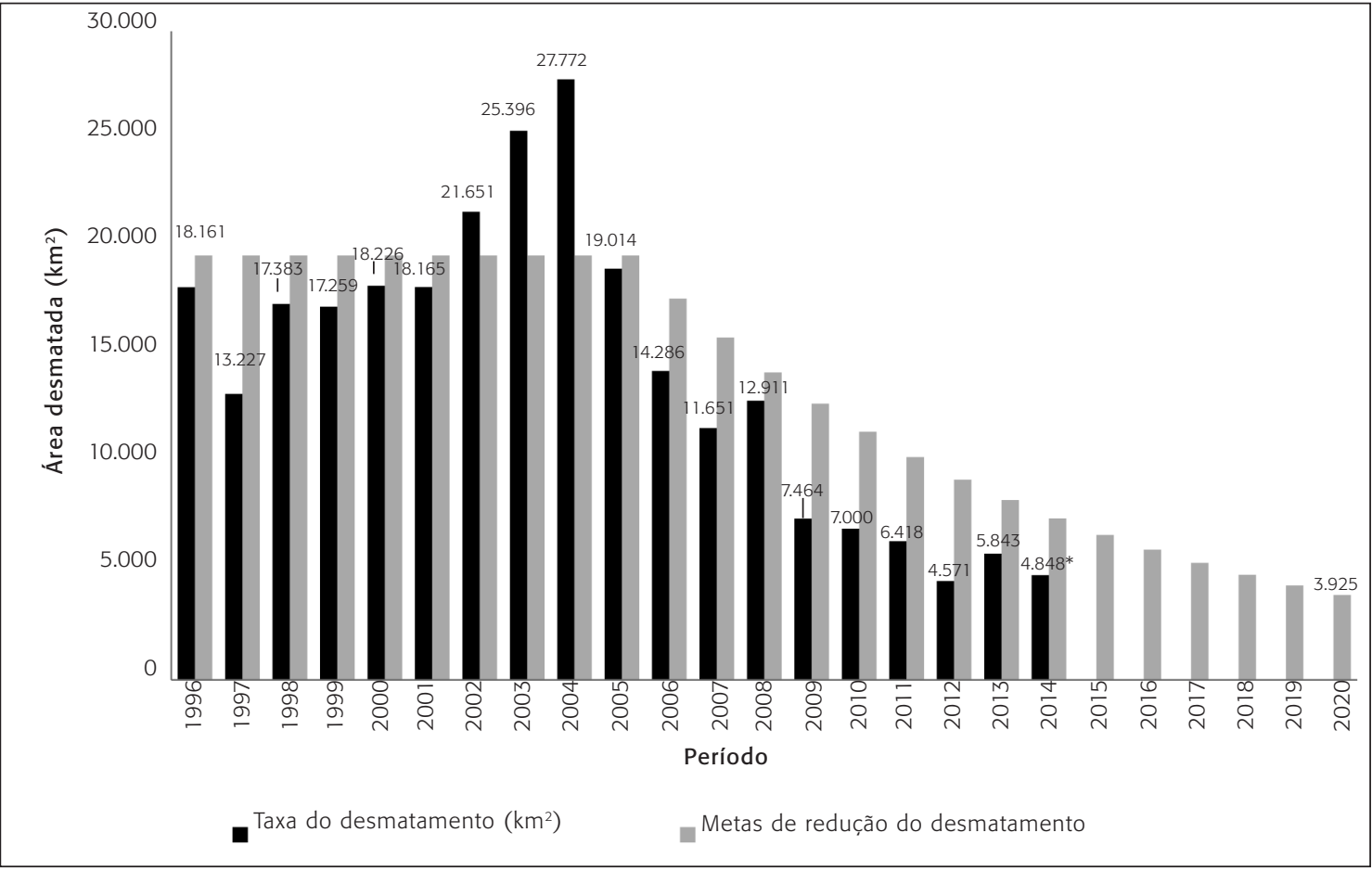

Fonte: Inpe (elaborado pelos autores).

O desmatamento na Amazônia é reflexo de uma série de eventos que se intensificaram nas últimas décadas do século XX e alguns deles se perpetuam até hoje. Em síntese, entre os principais fatores que impulsionam a realização de desmatamentos ilegais na Amazônia destacam-se:

a. O modelo de colonização da região desencadeou uma forte migração para Amazônia como válvula de escape para os problemas sociais de outras regiões e incentivos fiscais por meio de subsídios ao agronegócio (Hecht, 1985; Hecht e Cockburn, 1990; Schmink e Wood, 1992; Moran, 1993; Skole et al., 1994; Laurance, 1999, apud Soares Filho et al., 2005);

b. O domínio fundiário conflituoso devido à ausência de titularidade da terra e à pressão da reforma agrária (Fearnside, 1985, 2006). Até 2002, os assentamentos da reforma agrária na Amazônia ocupavam mais de $231 \mathrm{mil} \mathrm{km}^{2}$ e, destes, $106 \mathrm{mil} \mathrm{km}^{2}$ (49\%) já haviam sido desmatados decorrentes das atividades da agricultura e exploração madeireira, representando 15\% do desmatamento da Amazônia (Brandão Júnior e Souza Júnior, 2006);

c. O crescimento do agronegócio, em especial o da pecuária, que representa a maior motivação direta para o desmatamento (Margulis, 2002); 
d. Os investimentos em infraestrutura, sobretudo a abertura de estradas e pavimentação (Laurance et al., 2001), como as BR 163 (Cuibá-Santarém), BR 319 (Manaus-Porto Velho), BR 364 (Cruzeiro do Sul-Peru). As vias favorecem o desmatamento por promover a viabilidade econômica da pecuária e da agricultura e da exploração madeireira na Amazônia central, com consequente valorização de suas terras.

O Projeto TerraClass (Embrapa e Inpe, 2011) qualificou as áreas desflorestadas na Amazônia, o que resultou no mapeamento da situação do uso e da cobertura do solo no ano de 2008. Os dados indicam que, até aquela data, 17,8\% da floresta foi suprimida, o equivalente a mais de 719 mil km². Entre as principais classes, 62,2\% são áreas com algum tipo de pasto, $21 \%$ são compostos por vegetação secundária, o que indica regeneração da floresta, 4,9\% estão ocupados com agricultura, 0,5\% é de áreas urbanas, 3,4\% são mosaicos de ocupação e $0,1 \%$ é de áreas de mineração.

Mais recentemente, por meio da Política Nacional de Mudanças Climáticas (PNMC) (Brasil, 2009), o país assumiu o compromisso de reduzir as emissões de gases de efeito estufa projetadas até 2020. Sabe-se também que essas emissões decorrem em sua grande maioria do desmatamento e das queimadas na Amazônia. Assim, várias iniciativas foram empregadas para coibir o desmatamento ilegal, mas ainda o principal instrumento é fiscalização ambiental, ou seja, aplicação da lógica coercitiva do Estado.

As ações de fiscalização ambiental na Amazônia foram intensificadas a partir de 2004 com a implementação do Plano de Prevenção e Combate do Desmatamento na Amazônia (PPCDAM) (Brasil, 2003). Esse Plano foi elaborado pelo Grupo Permanente de Trabalho Interministerial composto inicialmente por 13 ministérios. No PPCDAM foram descritas ações estratégicas resultantes de quatro subgrupos: ordenamento fundiário e territorial, monitoramento e controle, fomento a atividades produtivas e sustentáveis, e infraestrutura. No subgrupo monitoramento e controle estão inseridas as ações de fiscalização ambiental.

\section{A fiscalização ambiental}

Visando melhor organizar e controlar a sociedade, uma das funções do Estado é exercer o poder de polícia. Tal poder "é faculdade que dispõe a administração pública para condicionar e restringir o uso e gozo de bens, atividades e direitos individuais, em benefício da coletividade e do próprio Estado" (Meirelles, 1987:93), ou seja, é a atividade do Estado que limita o exercício de direitos individuais em prol do bem comum (Di Pietro, 2012; Batista Júnior, 2001). No ordenamento jurídico, parece ser consensual entre a maioria dos doutrinadores brasileiros o uso do conceito de poder de polícia administrativa explícito no Código Tributário Nacional (Brasil, 1966).

Na área ambiental, o poder de polícia é exercido mais comumente por meio das ações de fiscalização, com medidas preventivas, de monitoramento, de inspeção, de advertência, punitivas, corretivas, entre outras. Assim, a lógica coercitiva da fiscalização ambiental reside 
na aplicação de sanções impostas por uma autoridade constituída pela sociedade, o Estado, e suas estruturas organizacionais. É, pois, a existência de uma ameaça de punição (sanção) pelo não cumprimento da regra e sua imposição por uma autoridade pública, que busca atender ao interesse geral, ou seja, o bem comum, a paz e a organização social (Lima, 1986). Estabelecese assim a coerção, ou seja, ato de induzir, pressionar ou compelir alguém a fazer algo pela força, intimidação ou ameaça. Esse direito de usar a força é um monopólio e uma prerrogativa legítima exercida pelo Estado moderno, conforme apregoa Weber (2003).

Um dos efeitos das sanções decorrentes do poder de polícia administrativa é o efeito de dissuasão, que consiste no temor da punição promovida pelo Estado, seja no indivíduo que cometeu uma infração ou a outros que possam cometê-la. Existem fatores importantes que podem influenciar a dissuasão, entre eles a certeza da punição, a severidade da pena, a celeridade da punição e a percepção da punição (Gomes e Garcia-Pablos de Molina, 2010; Siegel, 2008; Viapiana, 2006). A certeza da punição está relacionada à eficácia da administração pública em identificar as violações e aplicar as sanções aos responsáveis. A severidade da pena diz respeito à extensão das punições, supondo-se que, quanto mais longas ou mais rígidas elas forem, mais tendem a inibir o delito. E a celeridade da punição diz respeito à rapidez com que o Estado aplica e executa as sanções. Por último, para que os três primeiros elementos tenham seus efeitos potencializados é importante que a população os perceba de modo a fortalecer o efeito de dissuasão.

Em suma, a fiscalização ambiental, como uma atividade do poder de polícia administrativa ambiental, busca induzir a mudança do comportamento das pessoas por meio da coerção, de modo a evitar que novos danos ambientais venham a acontecer. Ou seja, quando um indivíduo não cumpre as regras de uso e não uso dos bens ambientais, o Estado, por meio do órgão de meio ambiente, pune o infrator. Logo, quando esse indivíduo tem de arcar com uma sanção pelo descumprimento da regra, ele tende a mudar de comportamento e não mais cometer violações. Essa situação tem um efeito multiplicador ao servir de exemplo para outros indivíduos que, na possibilidade de violarem as mesmas regras ambientais, também estão sujeitos às mesmas consequências. Desse modo, sentem-se inibidos, devido ao temor da punição.

Muitas das condutas lesivas ao meio ambiente têm origem em velhos vícios culturais e falta de consciência ambiental. Assim, entende-se que educar é mais nobre do que punir. Contudo, há casos em que a punição integra o processo pedagógico e quem exerce o poder de polícia administrativa ambiental deve estar preparado para as duas situações (Milaré, 2009). O modelo dissuasório (racionalista) também é carregado de críticas ao adotar uma lógica simplificada, desconhecendo que o impacto psicológico da punição não é uma magnitude uniforme, homogênea, linear, mas sim relativa às circunstâncias, que não são suscetíveis de juízo nem prognósticos generalizadores. Devido ao reducionismo, pode levar a uma inércia com rigores desmedidos como o efeito puramente intimidador, atemorizador e aterrorizador (Gomes e Garcia-Pablos de Molina, 2010). Além do modelo racionalista também existe o modelo normativo que postula o cumprimento ou não cumprimento das regras ambientais, 
decorrente do conhecimento dessas regras, da capacidade financeira e tecnológica dos atores e da percepção de que a regra é justa (Inece, 2009; Bemelmans-Videc, Rist e Vedung, 2003).

Conforme estabelece a lei sobre crimes e infrações ambientais (Brasil, 1998), compete aos servidores dos órgãos públicos integrantes do Sistema Nacional de Meio Ambiente (Sisnama) lavrar os autos de infração e instaurar os processos administrativos para apurar tais infrações. Assim, os órgãos municipais, estaduais, distritais e federais de meio ambiente, que são integrantes do Sisnama, podem aplicar as sanções administrativas para ações e omissões lesivas ao meio ambiente.

Na esfera federal o principal órgão de meio ambiente com o poder de fiscalizar é o Ibama que, entre suas finalidades, está previsto "exercer o poder de polícia ambiental", "executar ações das políticas nacionais de meio ambiente, referentes às atribuições federais, relativas (...) à fiscalização, monitoramento e controle ambiental" e "executar as ações supletivas de competência da União, de conformidade com a legislação ambiental vigente" (Brasil, 1989). Em 2007 foi criado o Instituto Chico Mendes de Conservação da Biodiversidade (ICMBio) que também goza da prerrogativa de fiscalizar, como autarquia responsável pela gestão das unidades de conservação federais.

O Ibama é instado pelo Ministério Público, pela Justiça ou mesmo por denúncias a atuar sobre todas as infrações ambientais, independente da magnitude do impacto ambiental, localização territorial, área ambiental ou competência. A repercussão disso é que, dada a lógica da descentralização, a instituição emprega sua capacidade instalada em ações que deveriam ser tratadas pelos demais entes federativos e deixa de realizar aquilo que é de sua competência primária. Isso afeta o foco de atuação institucional e corrobora para que os entes federativos não invistam em suas instituições para tratar dos problemas de suas competências. Por outro lado, ao não punir as infrações ambientais, forma-se uma percepção social de baixa eficácia da administração pública em proteger o meio ambiente por meio da coerção, o que pode induzir a mais infrações. $\mathrm{O}$ ideal seria que todos os entes federativos estivessem preparados para atender as demandas sociais.

Atualmente, as principais ações de fiscalização ambiental do Ibama continuam voltadas a combater o desmatamento ilegal na Amazônia. Secundariamente, outras áreas temáticas também são objeto de atuação da autarquia federal, como o combate aos ilícitos contra a pesca, fauna, acesso ao patrimônio genético, ilícitos transnacionais e os relacionados ao licenciamento ambiental.

Tendo em vista a conjuntura da administração pública e da temática ambiental no país, há grande preocupação com a capacidade de os entes federativos exercerem essas competências ambientais que lhes foi descentralizada (Nascimento e Bursztyn, 2011; Azevedo, Pasquis e Bursztyn, 2007; Bursztyn, Assunção e Bursztyn, 2004; Scardua e Bursztyn, 2003; Machado, 2002). Diante da frágil capacidade instalada de gestão ambiental nos estados e municípios, por conseguinte, de fiscalização ambiental, conforme demonstram o Instituto Brasileiro de Geografia e Estatística (IBGE, 2008), é de questionar se conseguirão manter a redução do desmatamento como vem ocorrendo por meio da fiscalização ambiental. Assim, para que a coerção administrativa possa ser efetiva e refletir na redução do desmatamento ilegal na 
Amazônia, algumas condições são essenciais para a estruturação dos órgãos ambientais na Amazônia, entre as quais:

a. Recursos financeiros: faz-se necessário o aporte de recursos financeiros para as novas tarefas descentralizadas. A esse respeito a LC 140 (Brasil, 2011) não fez nenhuma menção ao dispêndio (Antunes, 2012) e, mesmo após transcorrido mais de três anos da implementação da nova lei, não se vislumbra por parte da União qualquer aporte aos entes federados. Logo, a limitação financeira possivelmente implicará uma limitação operacional, pois, dificilmente, haverá maiores ações de fiscalização sem tais recursos. Além da possibilidade de orçamento próprio do ente federativo, há outras formas de fomento, tais como taxas administrativas e compensações decorrentes do licenciamento ambiental; recursos provenientes do pagamento de multas administrativas ambientais; fundos para o fomento de projetos ambientais; e o pagamento da taxa de controle e fiscalização ambiental. A respeito dessa última, foi criada com o propósito de auferir recursos para garantir o custeio e o financiamento das atividades realizadas pelo Ibama no exercício do poder de polícia ambiental (Martins, 2004). No entanto, o instrumento legal que a criou também previu que, na hipótese de haver algum tributo estadual equivalente, 60\% dos recursos arrecadados pelo órgão federal poderiam ser repassados aos estados sem que o contribuinte tivesse que arrecadar esse tributo estadual. Atualmente, são arrecadados cerca de 200 milhões de reais por ano e há um esforço do Ibama em realizar convênios com os estados para efetivar o repasse da parcela que cabe aos estados (Ibama, 2011);

b. Estrutura organizacional: é um instrumento administrativo que trata da forma que as instituições ambientais nos estados estão organizadas visando atingir seus objetivos. Na Amazônia, em geral, cada estado possui um órgão ambiental da administração direta, que trata da elaboração das políticas públicas e a ele está vinculada uma autarquia (administração indireta) que tem o papel de executar as políticas ambientais. As estruturas organizacionais de meio ambiente tiveram maiores avanços nos estados amazônicos a partir da década de 1990 com o apoio do Programa Piloto para Proteção das Florestas Tropicais do Brasil (PPG7), que é um programa institucional de cooperação técnica e financeira dos países desenvolvidos em parceria com o Brasil, na área de política ambiental nos estados da Amazônia. Entre as ações do PPG7 destaca-se o Subprograma de Políticas de Recursos Naturais (SPRN), que promoveu o fortalecimento dos órgãos estaduais de meio ambiente (Oema), o monitoramento, o controle e a fiscalização ambiental, e reforçou a participação e a descentralização como princípios da gestão ambiental, entre outros resultados (MMA, 2009). Nesse sentido, deveria haver uma estrutura organizacional mínima para atender as novas atribuições constitucionais, porém, a exemplo da gestão florestal, percebe-se que não se avançou quase nada;

c. Legislação: para o exercício da coerção administrativa é necessária uma estrutura normativa que estabeleça quais as condutas consideradas como infrações administrativas, as sanções e o rito de apuração dessas infrações. Na esfera federal o Decreto № 6.514 (Brasil, 2008) é o principal marco referencial, conjugado com outras normas editadas pelas autar- 
quias que apuram as infrações administrativas. Numa rápida análise, constata-se que os estados dispõem de normas próprias e que muitas vezes essas normas estabelecem sanções menos restritivas que as sanções aplicadas por órgãos federais. Assim, a princípio, parece ser mais vantajoso para o infrator ser punido por um órgão estadual do que por um órgão federal, isso sem considerar outras variáveis no processo de apuração da infração ambiental, tais como tempo de julgamento e mecanismos de execução das sanções, que também contribuem para a baixa perspectiva de efetividade do instrumento punitivo conduzido pelos Oema;

d. Informação: o insumo informacional é um dos principais ativos para se exercer a fiscalização ambiental. Sistemas de monitoramento ambiental são importantes para detectar anomalias no meio ambiente e possíveis transgressões às normas ambientais. Com base nessas informações é possível definir e planejar ações de fiscalização com mais precisão, voltada aos principais problemas que se quer conter. No caso do combate ao desmatamento ilegal na Amazônia, o Brasil conta com pelo menos dois sistemas de monitoramento executados pelo Instituto de Pesquisas Espaciais (Inpe), que são fundamentais para a atuação da fiscalização ambiental. Além disso, em atividades ilícitas mais complexas a informação é necessária para se sustentar o argumento administrativo da conduta ilícita, como em redes de tráfico de animais silvestres, a transação de produtos florestais, no acesso ao patrimônio genético, entre outros;

e. Servidores: por último, e não menos importante, o quadro de pessoal das instituições de meio ambiente é relevante no processo de descentralização ambiental e exercício da fiscalização, pois, com o incremento de novas atribuições, é inevitável ter que ampliar a força de trabalho, quantitativa e qualitativamente. Isso implicará realizar concursos públicos e capacitar continuamente os novos quadros, o que repercute também no aumento de despesas. Uma solução paliativa é o Oema realizar parcerias com as unidades de polícia militar ambiental, para que eles possam atuar no atendimento das ocorrências de ilícitos ambientais e na lavratura de autos de infração administrativa.

Convergente às necessidades anteriormente citadas, a Organização das Nações Unidas para Alimentação e Agricultura (FAO) também elegeu algumas condições para que a descentralização seja eficaz: recursos financeiros suficientes; poder das instituições para influenciar o sistema político e o desenvolvimento de atividades; mecanismos de responsabilização, transparência e representação; uma estrutura de leis e normas claras conferindo poderes e responsabilidades; e adequar a capacidade das instituições para prover bons serviços (FAO, 2002).

Como prevê a LC 140 (Brasil, 2011), quem deve fiscalizar o desmatamento e aplicar as sanções administrativas é quem detém a competência para autorizar a supressão vegetal para uso alternativo do solo ou para a exploração madeireira por meio do plano de manejo florestal sustentável, o que no caso são os estados e o Distrito Federal. Assim, em cerca de 85,6\% do desmatamento que ocorre na Amazônia, a responsabilidade de fiscalizar e aplicar as sanções administrativas são dos Oema e menos de 14,4\% são de competência dos órgãos 
federais (gráfico 2). Nesse último caso, o desmatamento ocorre em terras sob domínio da união (11\%), em unidades de conservação federais $(2,4 \%)$ e em terras indígenas (1\%). A fiscalização dos assentamentos da reforma agrária, que representam cerca de um terço de todo o desmatamento, é de responsabilidade dos estados, uma vez que são eles que licenciam os empreendimentos e autorizam a supressão da vegetação ou a exploração da madeira.

Prevalência da competência de fiscalização do desmatamento ilegal na Amazônia

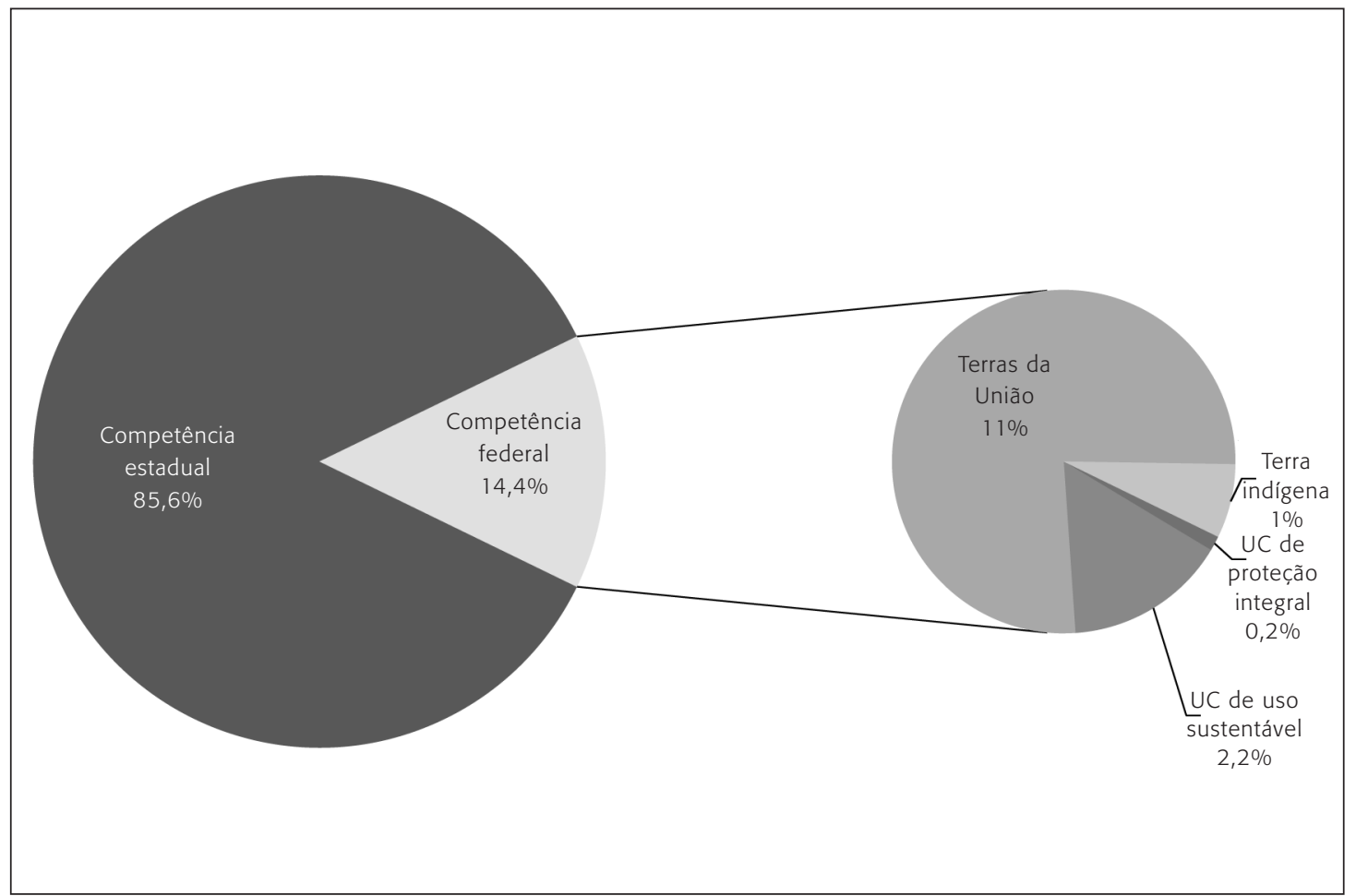

Fonte: Inpe, SBF e Ibama (elaborado por George P. Ferreira).

O Ibama lavra anualmente cerca de 20 mil autos de infração em todo o território, tendo como principal área geográfica de atuação a região Amazônica (Ibama, 2011). Embora não se tenham números precisos sobre a quantidade de autos de infração lavrados pelos órgãos ambientais dos entes federativos, estima-se que, somando todos os autos de infração ambiental dos 26 estados e do Distrito Federal, não totalizem a mesma monta que o órgão ambiental federal lavra anualmente. Abstraindo-se a atuação dos municípios, conclui-se que a maior parcela do esforço de fiscalização ambiental recai sobre o Ibama, o que faz dele também um órgão nacional e não um órgão federal, contrariando o modelo federativo do brasileiro. Observa-se que a priorização da atuação do Ibama no combate ao desmatamento ilegal na Amazônia acaba por causar uma distorção do que seria sua função, pois, em detrimento desse 
problema, que também é função dos estados, acaba não atendendo outros problemas que são de sua competência primária.

Além disso, Brito e Barreto (2006) realizaram um estudo na tentativa de avaliar a eficácia da aplicação da Lei de Crimes Ambientais pelo Ibama para proteção de florestas no Pará, tomando como amostra 55 processos de infrações ambientais iniciados no período de 1999 a 2000. Todavia, mesmo com o aumento dos esforços para proteger a floresta amazônica, explícitos no aumento dos autos de infração emitidos e no montante pecuniário dessas sanções, os resultados têm representado baixa eficácia da aplicação da referida lei. Isso é caracterizado porque $81 \%$ dos acusados são condenados na primeira instância, porém somente 3\% dos valores foram pagos. Entre os fatores apontados que contribuem para esse panorama está a insuficiência de pessoal para processar os casos, a insuficiência de meios legais de cobrança e a falta de medidas complementares de cobrança.

O Tribunal de Contas da União (TCU), ao realizar auditoria operacional, identificou diversos problemas na arrecadação de multas aplicadas pelo Ibama, entre eles havia erro de preenchimento em $80 \%$ dos autos de infração; deficiência da base de dados dos sistemas informatizados da arrecadação; inconsistência dos dados dos sistemas de trâmite processual; demora na análise de defesas (TCU, 1998). Em outra auditoria também foi constatado que os órgãos federais que atuam na Amazônia sofrem com a falta de infraestrutura e muitas vezes atuam em direções opostas (TCU, 2008). A auditoria em órgãos como Ibama, Instituto Nacional de Colonização e Reforma Agrária (Incra), Fundação Nacional de Saúde (Funasa), Fundação Nacional do Índio (Funai) e ICMBio identificou que a escassez de recursos e a falta de uma política integrada para a região têm consequências dramáticas resultando no desperdício de dinheiro público e na devastação acelerada da floresta. Como exemplo, é apontada a ineficiência do Ibama, traduzida na falta de fiscais, na demora para destinar bens apreendidos e na cobrança das multas aplicadas aos responsáveis.

Diante desses problemas, o quadro revela a precária ineficiência e ineficácia da fiscalização ambiental, o que pode comprometer o efeito de dissuasão almejado pela lógica coercitiva. Dessa forma, a perda da credibilidade institucional pode motivar o infrator a correr o risco de cometer o delito, ante a pequena possibilidade de ter que arcar com as sanções (multa, apreensão, embargo etc.). Na verdade, trata-se de melhorar o desempenho da administração pública para extrair melhores resultados dos instrumentos de gestão ambiental. Assim, se existem fragilidades no exercício do poder coercitivo do órgão federal que é considerado referência no combate ao desmatamento, o que dizer dos demais órgãos dos entes federativos? Diante da capacidade instalada também frágil nos estados que compõem a região amazônica, é de se questionar que consigam manter a redução do desmatamento que se registrou nesses últimos cinco anos. Por isso a preocupação.

Outro aspecto que incita temores é de que exercer o poder de polícia administrativa valendo-se da coerção para promover a proteção ambiental é uma "agenda cinza", pois politicamente não é interessante, para os grupos dominantes locais, punir aqueles que lhes garantem o voto. Essa ideia é ressalvada quando se busca fiscalizar e punir um infrator pertencente a um grupo político de oposição. Assim, a descentralização apresenta-se como um fenômeno de 
distribuição de poder, sobretudo, de execução (Vieira, 2012) e que, muitas vezes, pode haver a captura desse poder sem atingir seu objetivo.

\section{Conclusão}

Com a promulgação da LC 140 (Brasil, 2011), foi disciplinada a descentralização das competências em meio ambiente entre os entes federativos, buscando deixar mais explícita a atuação de cada um deles, dando maior clareza ao texto constitucional. Tal avanço do ordenamento jurídico condiz com o modelo federativo do Estado brasileiro cujos alicerces estavam definidos desde a instituição da atual CF. Durante esse período também se obtiveram vários avanços na área ambiental mas, por outro lado, a governança parecia estar desmedida com a concentração de poderes à União sobre assuntos estritamente locais. Os fatores econômico e desenvolvimentista foram os que deram propulsão à mudança, com um dos argumentos de que as licenças ambientais para as grandes obras as tornavam morosas ou inviáveis.

Estabelecida a descentralização, o arcabouço legal foi fundamentalmente pautado pelo licenciamento ambiental de atividades e empreendimentos. Ocorre que a ação coercitiva do Estado, exercida na atividade de fiscalização, foi vinculada à lógica de fiscalizar e punir aquilo que se licencia ou autoriza. Isso é positivo à medida que força o órgão responsável por determinado objeto ambiental a tratar melhor o problema das infrações administrativas. Ao definir o papel de cada ente federado com mais clareza, possibilita que o órgão ambiental se concentre e dê foco ao seu problema, diferente da situação anterior onde todos tinham praticamente a mesma obrigação de fiscalizar tudo. Consequentemente, com mais foco, pode-se obter mais qualidade (eficácia) nos produtos e serviços desenvolvidos. Assim, num cenário onde todos podem fiscalizar tudo (ou poderiam), ninguém tem estrutura o suficiente para fazê-lo.

Essa eficácia é extremamente necessária para a lógica coercitiva, pois, quando não há a certeza da punição, diminui o risco para o infrator e aumenta a probabilidade de cometimento de infrações. Com a nova regra firmada pela LC 140 (Brasil, 2011), em relação à competência de fiscalizar o desmatamento ilegal na Amazônia, é fático que a responsabilidade de apurar a maior parte dessas infrações é dos estados, uma vez que são eles que têm a competência para autorizar os desmatamentos e a exploração florestal. Contudo, é o órgão federal (Ibama) que tem despendido o maior esforço de fiscalização para conter essa conduta social indesejada, o que implica duas situações.

A primeira é que, se o Ibama continuar a exercer supletivamente o papel dos estados em fiscalizar o desmatamento ilegal, vai ocupar sua capacidade instalada com esse problema e não terá disponibilidade de meios para executar aquilo é de sua competência primária, ou seja, a LC 140 (Brasil, 2011) não será de fato implementada. E, segundo, caso o Ibama foque sua atuação apenas nas suas competências primárias e deixe de fiscalizar a parcela do desmatamento ilegal que é de competência dos estados, é provável que o desmatamento volte a crescer e perpetuar o dano ambiental. Essa segunda situação é fundamentada na falta de estrutura dos órgãos estaduais de meio ambiente que é notória e declarada, e até mesmo na 
falta de interesse, visto que empregar o instrumento punitivo tem elevados custos e também gera controvérsias políticas.

Logo, conter o desmatamento ilegal na Amazônia continua sendo um impasse na gestão ambiental pública, mesmo com o disciplinamento gerado pela LC 140 (Brasil, 2011), pois, enquanto os órgãos ambientais não estiverem efetivamente estruturados e compromissados com suas competências, o meio ambiente sofrerá as externalidades negativas. Resta claro que o instrumento coercitivo, exercido por meio da atividade de fiscalização ambiental, só terá maior efetividade se os órgãos ambientais mudarem sua forma de agir, independente da esfera administrativa (federal, estadual, municipal). Por parte da União há a necessidade de se adaptar a capacidade instalada à nova realidade, o que exige reorientar os planos de trabalho, preparar os servidores para as novas atividades e planejar novas estratégias de ação.

Assim, em que pese haver a possibilidade da atuação supletiva ou subsidiária dos órgãos federais na fiscalização ambiental, entende-se que esses dispositivos só deveriam ser empregados em casos fortuitos, como na etapa de adaptação dos entes federativos à nova legislação. Nesse caso, também seria importante que a União e mesmo os estados trabalhassem para viabilizar a implementação das novas competências apoiando a capacitação de servidores, com aporte financeiro, orientação técnica, organização de processos de trabalho, elaborando e uniformizando normas e procedimentos etc.

Diante da descentralização ambiental, o papel que se idealiza para o Ibama, como principal órgão executor do instrumento coercitivo para o combate ao desmatamento ilegal na Amazônia, é uma atuação focada em suas competências primárias e, excepcionalmente, quando esgotada a atuação dos estados e municípios, ele poderá atuar supletivamente. Ademais, vislumbra-se que, como órgão importante do Sisnama, como membro do Conama ou mesmo das Comissões Bipartite e Tripartites, ele poderá desempenhar um papel mais relevante na formulação de políticas públicas voltadas ao controle e proteção ambiental. Também poderá atuar auxiliando a estruturação dos demais órgãos ambientais, dada a experiência acumulada ao longo da sua trajetória.

Por último, de maneira geral, é necessário refletir e buscar novas respostas para o impasse que há tempos preocupa a sociedade: como conter o desmatamento na Amazônia? A princípio, o instrumento coercitivo (desestímulos) tem trazido alguns resultados positivos, mas parece não ser a solução plena para o problema. Existem muitas variáveis que não estão sendo devidamente tratadas, ou se esperam apenas resultados em curto prazo. As ciências comportamentais defendem que a mudança de comportamento também deve ocorrer por meio de estímulos (Sidman, 2011), visto que a coerção também traz implicações negativas à sociedade. Assim, um dos estímulos que o Estado poderia prover seria o financeiro, como o pagamento por serviços ambientais para a manutenção da floresta. Esse tipo de estímulo poderia se contrapor à vantagem econômica que motiva a infração ambiental (Becker, 1968) do desmatamento para a produção pecuária, agrícola ou a exploração florestal.

Embora pareçam existir algumas dificuldades para se conter o desmatamento ilegal na Amazônia, a descentralização das competências em ambiente configura um novo cenário com muitas oportunidades de melhoria à sociedade. Combates a determinados tipos de infrações 
antes ignorados agora passam a ser prioridades com a possibilidade de desafogar uma ampla gama de demandas.

\section{Referências}

ANDERSEN, George. O federalismo: uma introdução. São Paulo: FGV, 2009.

ANDERSSON, Krister P.; OSTROM, Elinor. Analyzing decentralized resource regimes from a polycentric perspective. Policy Sciences, v. 41, n. 1, p. 71-93, 2008.

ANTUNES, Paulo B. Direito ambiental. 14. ed. São Paulo: Atlas, 2012.

ARRETCHE, Marta T. S. O mito da descentralização: maior democratização e eficiência das políticas públicas? Revista Brasileira de Ciências Sociais, v. 11, n. 31, p. 44-66, 1996.

AZEVEDO, Andréa; PASQUIS, Richard; BURSZTYN, Marcel. A reforma do Estado, a emergência da descentralização e as políticas ambientais. Revista do Serviço Público, v. 1, n. 58, p. 37-55, 2007.

BAKER, Mark. The Kuhls of Kangra: community-managed irrigation in the western Himalaya. Seattle, WA: University of Washington Press, 2005.

BATISTA JÚNIOR, Onofre Antonio. O poder de polícia fiscal. Belo Horizonte: Mandamentos, 2001.

BECKER, Gary S. Crime and punishment: an economic approach. The Journal of Political Economy, v. 76, n. 2, p. 169-217, 1968.

BEMELMANS-VIDEC, Marie-Louise; RIST, Ray C.; VEDUNG, Evert (Ed.). Carrots, sticks and sermons: policy instruments and their evaluation. Londres: Transaction Publishers, 2003.

BRANDÃO JÚNIOR, Amintas; SOUZA JÚNIOR, Carlos. Desmatamento nos assentamentos de reforma agrária na Amazônia. Disponível em: <http://imazon.org.br/desmatamento-nos-assentamentosde-reforma-agraria-na-amazonia/\# ancora1>. Acesso em: 20 dez. 2006.

BRASIL. Constituição da República Federativa do Brasil: texto constitucional promulgado em 5 de outubro de 1988. Brasília: Senado Federal, 2010.

BRASIL. Decreto no 6.514, de 22 de julho de 2008. Diário Oficial da República Federativa do Brasil, Brasília, 3 jul. 2008. Seção 1. Disponível em: <www.in.gov.br>. Acesso em: 2 jan. 2015.

BRASIL. Decreto s/n, de 03 de junho de 2003. Diário Oficial da República Federativa do Brasil, Brasília, 4 jun. 2004. Seção 1. Disponível em: <www.in.gov.br>. Acesso em: 1o jan. 2012.

BRASIL. Lei no 5.172, de 25 de outubro de 1966. Diário Oficial da República Federativa do Brasil, Brasília, 27 out. 1966. Seção 1. Disponível em: <www.in.gov.br>. Acesso em: 1o jul. 2008.

BRASIL. Lei no 6.938, de 31 de agosto de 1981. Diário Oficial da República Federativa do Brasil, Brasília, 2 set. 1981. Seção 1. Disponível em: <www.in.gov.br>. Acesso em: 2 jan. 2015. 
BRASIL. Lei no 7.735, de 22 de fevereiro de 1989. Diário Oficial da República Federativa do Brasil, Brasília, 23 fev. 1989. Seção 1. Disponível em: <www.in.gov.br>. Acesso em: 1o jan. 2012.

BRASIL. Lei no 9.605, de 12 de fevereiro de 1998. Diário Oficial da República Federativa do Brasil, Brasília, 13 fev. 2006. Seção 1. Disponível em: <www.in.gov.br>. Acesso em: 1o jan. 2012.

BRASIL. Lei $n^{\circ}$ 11.284, de 2 de março de 2006. Diário Oficial da República Federativa do Brasil, Brasília, 3 mar. 2006. Seção 1. Disponível em: <www.in.gov.br>. Acesso em: 1 jan. 2012.

BRASIL. Lei no 12.187, de 29 de dezembro de 2009. Diário Oficial da República Federativa do Brasil, Brasília, 30.12.2009. Seção 1. Disponível em: <www.in.gov.br>. Acesso em: 1ํo mar. 2013.

BRASIL. Lei ํo 12.651, de 25 de maio de 2012. Diário Oficial da República Federativa do Brasil, Brasília, 28 maio 2012. Seção 1. Disponível em: <www.in.gov.br>. Acesso em: 11 jan. 2012.

BRASIL. Lei Complementar no 140, de 8 de dezembro de 2011. Diário Oficial da República Federativa do Brasil, Brasília, 9 dez. 2012. Seção 1. Disponível em: <www.in.gov.br> . Acesso em: 1ํjan. 2012.

BRITO, Brenda; BARRETO, Paulo. A eficácia da aplicação da lei de crimes ambientais pelo Ibama para proteção de florestas no Pará. Revista de Direito Ambiental, v. 1, n. 46, p. 35-45, 2006.

BURSZTYN, Maria A. A.; ASSUNÇÃO, Francisca N. A.; BURSZTYN, Marcel. Aspectos legais e institucionais da gestão ambiental na Amazônia. In: SAYAGO, Doris; TOURRAND, Jean F.; BURSZTYN, Marcel (Org.). Amazônia: cenas e cenários. Brasília: Editora UnB, 2004. p. 263-294.

CAPES. Coordenação de Aperfeiçoamento de Pessoal de Nível Superior. Portal de periódicos da Capes. Disponível em: <www.periodicos.capes.gov.br/>. Acesso em: 14 jan. 2012.

CONAMA. Conselho Nacional de Meio Ambiente. Resolução no 273, de 29 de novembro de 2000. Diário Oficial da República Federativa do Brasil, Brasília, 30 nov. 2000. Seção 1. Disponível em: <www.in.gov.br>. Acesso em: 11 jan. 2012.

DI PIETRO, Maria S. Z. Direito administrativo. 25. ed. São Paulo: Atlas, 2012.

EMBRAPA. Empresa Brasileira de Pesquisa Agropecuária; INPE. Instituto Nacional de Pesquisas Espaciais. Levantamento de informações de uso e cobertura da terra na Amazônia: sumário executivo. Brasília: Embrapa; Inpe, 2011.

EPSTEIN, Richard A. Enforcing norms: when the law gets in the way. The Responsive Community, n. 7, p. 4-15, 1997.

FAO. Food and Agriculture Organization of the United Nations. Environment in decentralized development: economic and institutional issues. Rome: FAO, 2002.

FEARNSIDE, Philip. Agriculture in Amazonia. In: PRANCE, Ghillean T.; LOVEJOY, Thomas E. (Ed.). Key environments of Amazonia. Oxford: Pergamon Press, 1985. p. 393-418.

FEARNSIDE, Philip. Desmatamento na Amazônia: dinâmica, impactos e controle. Acta Amazônica, v. 36, n. 3, p. 395-400, 2006. 
GIBSON, Clark C.; LEHOUCQ, Fabrice. The local politics of decentralized environmental policy in Guatemala. Journal of Environment and Development, v. 12, n. 1, p. 28-49, 2003.

GOMES, Luiz F.; GARCIA-PABLOS DE MOLINA, Antonio. Criminologia: introdução a seus fundamentos teóricos. 7. ed. São Paulo: Revista dos Tribunais, 2010.

HECHT, Susanna B. Environment, development and politics: capital accumulation and livestock sector in Eastern Amazonia. Word Development, v. 13, n. 6, p. 663-684, 1985.

HECHT, Susanna B.; COCKBURN, Alexander. The fate of the forest: developers, destroyers and defenders of the Amazon. Nova York: Harper Perennial, 1990. p. 357.

HOCHSTETLER, Kathryn; KECK, Margaret E. Greening Brazil: environmental activism in state and society. Durham, NC: Duke University Press, 2007.

IBAMA. Instituto Brasileiro do Meio Ambiente e dos Recursos Naturais Renováveis. Sistema de cadastro, arrecadação e fiscalização. Brasília: Ibama, 2011.

IBGE. Instituto Brasileiro de Geografia e Estatística. Pesquisa de informações básicas municipais (Munic). Perfil dos municípios brasileiros - 2008. Rio de Janeiro: IBGE, 2008.

INECE. International Network for Environmental Compliance and Enforcement. Principles of environmental compliance and enforcement handbook, 2009. Disponível em: <www.inece.org/principles/ PrinciplesHandbook_23sept09.pdf>. Acesso em: 10 ago. 2012.

INPE. Instituto Nacional de Pesquisas Espaciais. Monitoramento da floresta amazônica brasileira por satélite. Disponível em: <www.obt.inpe.br/prodes/index.php>. Acesso em: 20 dez. 2014.

JOHNSON, Craig. Community formation and fisheries conservation in Southern Thailand. Development and Change, v. 32, n. 5, p. 951-974, 2001.

LAURANCE, William F. Reflections on tropical deforestation crisis. Biological Conservation, v. 91, n. 2-3, p. 109-117, 1999.

LAURANCE, William F. et al. The future of the Brazilian Amazon. Science, v. 1, n. 291, p. 438-439, 2001.

LIBECAP, Gary D. Distributional issues in contracting for property rights. Journal of Institutional and Theoretical Economics, v. 145, n. 1, p. 6-24, 1989.

LIMA, Hermes. Introdução à ciência do direito. 28. ed. Rio de Janeiro: Freitas Bastos, 1986.

MACHADO, Paulo A. L. Direito ambiental brasileiro. 10. ed. São Paulo: Malheiros, 2002.

MANN, Peter H. Métodos de investigação sociológica. 3. ed. Rio de Janeiro: Zahar, 1975.

MARGULIS, Sérgio. Quem são os agentes dos desmatamentos na Amazônia e por que eles desmatam? Word Bank internal paper, 2002. Disponível em: <www.obancomundial.org/index.php/content/ view_folder/87.html>. Acesso em: 4 ago. 2008.

MARTINS, Leonardo R. Constitucionalidade da Taxa de Controle e Fiscalização Ambiental (TCFA). Revista Esmafe, v. 6, n. 1, p. 189-198. 2004. 
MEINZEN-DICK, Ruth. Beyond panaceas in water institutions. PNAS, v. 104, n. 39, p. 15200-15205, 2007.

MEIRELLES, Hely L. Direito administrativo brasileiro. 13. ed. São Paulo: Revista dos Tribunais, 1987. MILARÉ, Édis. Direito do meio ambiente: a gestão ambiental em foco - doutrina, jurisprudência, glossário. 6. ed. São Paulo: Revista dos Tribunais, 2009.

MMA. Ministério do Meio Ambiente. Caminhos para a sustentabilidade: as contribuições do maior programa ambiental do país para o uso e a proteção das florestas tropicais brasileiras. MMA: Brasília, 2009.

MORAN, Emilio. F. Deforestation and land use in the Brazilian Amazon. Human Ecology, v. 1, n. 21, p. 1-21, 1993.

NASCIMENTO, Daniel T.; BURSZTYN, Maria A. A. Descentralização da gestão ambiental: análise do processo de criação de organizações municipais de meio ambiente no sul catarinense. Revista do Serviço Público, v. 2, n. 62, p. 185-208, 2011.

PLATTEAU, Jean-Philippe. Monitoring elite capture in community-driven development. Development and Change, v. 35, n. 2, p. 223-246, 2004.

PLATTEAU, Jean-Philippe; GASPART, Frederic. The risk of resource misappropriation in community-driven development. Word Development, v. 31, n. 10, p. 1687-1703, 2003.

SCARDUA, Fernando P.; BURSZTYN, Maria A. A. Descentralização da política ambiental no Brasil. Sociedade e Estado, v. 18, n. 1-2, p. 257-290, 2003.

SCHMINK, Marianne; WOOD, Charles H. Contested frontiers in Amazon. Nova York: Columbia University Press, 1992.

SHIVAKUMAR, Sujai. The constitution of development: crafting capabilities for self-governance. Nova York: Palgrave MacMillan, 2005.

SIDMAN, Murray. Coerção e suas implicações. Campinas: Livro Pleno, 2011.

SIEGEL, Larry J. Criminology. 10. ed. Belmont: Thomson Higher Education, 2008.

SKOLE, David L. et al. Physical and human dimensions of deforestation in Amazonia. BioScience, v. 44, n. 5, p. 314-322, 1994.

SOARES FILHO, Britaldo S. et al. Cenários de desmatamento para a Amazônia. Estudos Avançados, v. 19, n. 54, p. 137-152, 2005.

TCU. Tribunal de Contas da União. Relatório de auditoria de desempenho. Processo TC-930.263/19987. Brasília: TCU, 1998.

TCU. Tribunal de Contas da União. Relatório de auditoria operacional. Processo TC-019.720/20073. Brasília: TCU, 2008.

TEIXEIRA, Hélio J.; SANTANA, Solange. M. Remodelando a gestão pública. São Paulo: Edgard Blücher, 1995. 
VIAPIANA, Luiz T. Economia do crime: uma explicação para a formação do criminoso. Porto Alegre: AGE, 2006.

VIEIRA, Paulo R. Em busca de uma teoria de descentralização. Rev. Adm. Pública, v. 46, n. 5, p. 409-425, 2012.

WEBER, Max. A política como vocação. Brasília: UnB, 2003.

Jair Schmitt é doutorando do Programa de Pós-Graduação em Desenvolvimento Sustentável, Centro de Desenvolvimento Sustentável (CDS), Universidade de Brasília (UnB). E-mail: jair.schmitt@gmail.com.

Fernando Paiva Scardua é doutor em desenvolvimento sustentável, Centro de Desenvolvimento Sustentável (CDS), Universidade de Brasília (UnB). Professor adjunto da Faculdade UnB Gama, Universidade de Brasília. E-mail: fscardua@unb.br. 